AperTO - Archivio Istituzionale Open Access dell'Università di Torino

\title{
MOOCs for Mathematics Teacher Education to Foster Professional Development: Design Principles and Assessment
}

\section{This is the author's manuscript}

Original Citation:

\section{Availability:}

This version is available http://hdl.handle.net/2318/1710584

since 2019-08-27T11:01:27Z

Publisher:

Springer Nature

Published version:

DOI:10.1007/978-3-030-19741-4_10

Terms of use:

Open Access

Anyone can freely access the full text of works made available as "Open Access". Works made available under a Creative Commons license can be used according to the terms and conditions of said license. Use of all other works requires consent of the right holder (author or publisher) if not exempted from copyright protection by the applicable law. 


\section{MOOCS FOR MATHEMATICS TEACHER EDUCATION TO FOSTER PROFESSIONAL DEVELOPMENT: DESIGN PRINCIPLES AND ASSESSMENT}

${ }^{1}$ Gilles Aldon, ${ }^{2}$ Ferdinando Arzarello, ${ }^{1,3}$ Monica Panero, ${ }^{2}$ Ornella Robutti, ${ }^{2,4}$ Eugenia Taranto, ${ }^{5}$ Jana Trgalová

${ }^{1}$ S2HEP-EducTice, Institut Français de l'Education, ENS de Lyon, France, ${ }^{2}$ Department of Mathematics, University of Turin, Italy, ${ }^{3}$ Department of Education and Learning, SUSPI, Switzerland, ${ }^{4}$ Department of Educational Science, University of Catania, Italy, ${ }^{5}$ Claude Bernard University Lyon 1, S2HEP (EA4148), France;

gilles.aldon@ens-lyon.fr, ferdinando.arzarello@unito.it,monica.panero@supsi.ch, ornella.robutti@unito.it, eugenia.taranto@unict.it,jana.trgalova@univ-lyon1.fr

ABSTRACT: In this chapter we report on an ongoing international research about MOOCs for inservice mathematics teacher professional development. We describe and analyse two different experiences of this kind: two seasons of the Italian Math MOOC UniTo (Geometria MOOC and Numeri MOOC) and two seasons of the French eFAN Maths MOOC. Both MOOCs aimed at supporting teachers' professional development through a suitable mediation of technology. They also aimed at triggering as much as possible the teachers' engagement in order to develop one or more teachers' communities of practice. Starting from our methodological choices, as trainers, we propose some reflections about design principles of MOOCs for mathematics teacher education using the theoretical lens of the Meta-Didactical Transposition (Arzarello et al. 2014). These reflections focus on trainers' practices to foster participation and collaboration among trainees and to assess efficiently this kind of engagement.

Keywords: MOOC, design principles, project-based assessment, teacher professional development

\section{INTRODUCTION}

The emergence of Massive Open Online Courses (MOOCs) in 2008, enabled by technology and social networking, has opened new educational possibilities. McAuley et al. (2010, p. 10) define a MOOC as "an online course with the option of free and open registration, a publicly shared curriculum, and open-ended outcomes". The authors put forward that "a MOOC builds on the active engagement of several hundred to several thousand students who self-organize their participation according to learning goals, prior knowledge and skills, and common interests" (ibid.).

These distinguishing features, which some actors of education consider as revolutionizing and transforming education (Fidalfo-Blanco et al., 2015), challenge a number of aspects like pedagogical design, roles of teacher/trainer and student/trainee in these massive courses, monitoring learners' activity and performance, validation and accreditation etc.

According to the pedagogical model, MOOCs can be classified in three main categories: xMOOCs, e.g., Coursera ${ }^{1}$ or Udacity ${ }^{2}$, that are designed on a pedagogical model "dominated by the "drill and grill' instructional methods with video presentations, short quizzes and testing" (Yuan and Powell,

\footnotetext{
1 https://about.coursera.org/

2 https://www.udacity.com/
}

Springer book 
2013, p. 7); cMOOCs or connectivist MOOCs, e.g., CCK $11^{3}$, that are "based on a connectivism theory of learning with networks developed informally" (ibid.) and a participative pedagogical model; and quasi-MOOCs, e.g., Khan academy ${ }^{4}$ or Didattica della Matematica ${ }^{5}$, which provide online open educational resources aiming at supporting learning-specific tasks and do not offer social interaction of cMOOCs or a structured course of xMOOCs (Siemens, 2013, p. 8).

Although there is a wide choice of topics covered by more than 6800 MOOCs available worldwide (in 2016) ${ }^{6}$, the use of MOOCs for teacher professional development is still uncommon. Nevertheless, there is a growing interest in designing technology-mediated teacher professional development programs (Brooks \& Gibson, 2012). These initiatives highlight the importance of combining instruction with peer community learning, which can be well fitted in MOOCs, according to Laurillard (2016) who claims that "if the MOOC format is to be an effective mechanism for promoting educational innovation it must be able to support a co-learning model of professional development for the community of teachers".

In this chapter we report about the experience of three MOOCs for mathematics teacher professional development: the eFAN Maths MOOC, designed in France and aimed at supporting teachers to integrate digital resources and technology in their classes; and two MOOCs designed in Italy, Geometria and Numeri, aimed at fostering mathematics teachers' professional development with the use of innovative practice for teaching geometry, arithmetic and algebra, also using Dynamic Geometry System (DGS), e.g. GeoGebra. These MOOCs aspire at creating collaborative contexts for teachers' work, where they can learn through sharing their practices and working collaboratively on joint tasks. Taking into account the necessity for teachers to be supported in exploiting technological affordances, the objectives of such MOOCs are: accompanying teachers in the production of teaching resources, by examples of activities and reflection on their ongoing resource design; fostering a sound use of technology, encouraging teachers to choose proper digital tools for the classroom; sharing innovative didactical practices. Such aims are related to the interest in the design and the implementation of teacher professional development programs to include the role of teachers working and learning in communities (Wenger, 1998; Jaworski \& Goodchild, 2006).

The originality of our research resides in those design principles that are relevant and useful to mediate teachers' professional development courses with technology, and in the assessment of the impact of such distance courses on mathematics teachers' engagement. A specific attention is paid on trainers and their role in supporting interactions and learning communities that emerged during the MOOC. Trainers' techniques and their evolution are presented and analyzed in order to highlight and discuss their methodological and theoretical justifications.

\title{
2. DESCRIPTION OF THE MOOCS
}

\subsection{Four dimensions of collaborative work}

For the description of the MOOCs, we use the frame introduced in the recent ICME survey (Robutti et al., 2016), focused on learning that occurs when mathematics teachers work together collaboratively. It is based on three themes: i) contexts and features of mathematics teachers working collaboratively; ii) theories and methodologies; and iii) outcomes. The first theme is the

\author{
http://cck11.mooc.ca/ \\ https://www.khanacademy.org/ \\ https://www.youtube.com/user/DIFIMARobutti \\ https://www.class-central.com/report/mooc-stats-2016/
}

Springer book 
one that we will use in this chapter to introduce the experiences of the different MOOCs. This theme is particularly useful in framing the educational initiative, because it is spread out in different dimensions that give specific information on MOOCs' birth, structure, and participants, which are:

1) The initiation, foci and aims of collaborations;

2) The scale of collaborations (numbers of teachers and time-line);

3) The composition of collaborative groups and the roles of the participants;

4) Collaborative ways of working and their conception.

In what follows, we present the experiences of MOOCs according to this frame, in order to contextualize them in a general perspective. The reason is that the (numerous) teachers involved in these MOOCs collaborated intensely, although not in a face-to-face modality, but rather through a platform in order to accomplish the tasks presented by the trainers. In addition, the teachers spontaneously collaborated, according to their professional needs, roles, and competencies, and worked together in various ways: following the structure of the MOOCs, using the available technological tools. Working together they learnt, because they were involved in various kinds of knowledge (content, pedagogical, technological, and institutional).

\subsection{Geometria and Numeri, the Italian MOOCs}

\subsubsection{Initiation, foci and aims of collaboration}

From spring 2015, at the Mathematics Department of Turin University, the Math MOOC UniTo project has come to life. It is the result of a long development process over many years by the researchers of the Department and characterized by many previous experiences of teacher education projects in which the team has been involved (e.g. the m@t.abel project ${ }^{7}$ ) alongside years of research on teacher education. Math MOOC UniTo project consists in the design and delivery of MOOCs for education and professional development of in-service mathematics teachers of secondary school (both lower and higher). In particular, the Italian MOOCs are for teachers and designed by teachers, in collaboration with university researchers. The teacher-designers previously attended a Master on Mathematics Education and innovation, based on the didactical material from the m@t.abel project. After this experience, a fresh need emerged from those who had concluded the Master: awareness of the need to support teaching activities with teacher education; willingness to develop best practices of innovation using software; reconsidering in terms of learning social media mostly used by the students. Hence, it was decided to offer the opportunity of an authentic professional development experience designed for a larger group of teachers that could become a community of practice (Wenger, 1998).

\subsubsection{Scale of collaboration (number of teachers and timeline)}

The first two MOOCs (others are following them: Relations and Functions in 2018) delivered are open, free and available online on the Moodle platform DI.FI.MA. (Didactics of Physics and Mathematics ${ }^{8}$ ) and make use of open source tools (e.g. GeoGebra), enabling teachers to easily adapt to them in their teaching practices.

The Geometria MOOC was on geometry and its 424 participants were secondary school teachers from all over Italy. It lasted 8 weeks plus 2 weeks for accomplishing the final tasks: from October 2015 to January 2016. The Numeri MOOC was on arithmetic and algebra, with 278 participants,

\footnotetext{
7 http://www.scuolavalore.indire.it/superguida/matabel/

8 http://difima.i-learn.unito.it/
}

Springer book 
secondary school teachers from all over Italy. It was delivered during 6 weeks plus 4 weeks for accomplishing the final tasks: from November 2016 to January 2017 . Percentages of $36 \%$ and $42 \%$ of teachers completed all of the Geometria and Numeri MOOCs activities respectively, which is quite high completion rate compared to the current average completion rate for MOOCs that is approximately $15 \%{ }^{9}$.

\subsubsection{Composition of collaborative groups and participants' roles}

Within the Italian MOOCs, and in general within MOOCs for teacher education, two communities can be distinguished. On the one hand, there are trainers (two university professors, about 15 inservice teachers enrolled in the Master in Mathematics Education and a PhD student); all of them were involved in the design, the course delivery and monitoring its evolution in terms of interaction among participants and educational resources made available. In particular, the 15 teachers also created the activities delivered in the MOOCs, adapted from m@tabel project and revised by the university professors. Moreover, the trainers helped trainees to solve technical problems, made tutorials, recalled the tasks to be done week by week with weekly emails. On the other hand, there are trainees (the teachers enrolled in the MOOC); they have an active role in learning not only the activities and methodologies proposed but also in using technological tools for interaction. In fact, every week the trainees are assigned an individual work and used environments and methodologies at different levels, in order to collect their weekly badges. These activities include: watching a video where an expert introduced the conceptual knot of the week; watching a "cartoon video" with some guidelines to carry out the units; reading the activities based on a mathematics laboratory (and the option to experiment with these in their classroom); doing multiple choice questions (MCQs) on the themes of the week. Moreover, they have to use suitable communication message boards (Forum, Padlet, Tricider) to express opinions about the content of the course, exchange experiences with colleagues, and benefit from other participants' ways of thinking. In both Italian MOOCs there were a collaborative climate and, surprisingly (for the trainers), some of the participants started voluntarily sharing material they created and were using in their lessons. The team of trainers chose to limit their own interventions in these message boards to a minimum in order to support the birth of a trainees-only online community of practice (Wenger, 1998). The trainers were more active within the webinars: educational online events for trainees.

Each Italian MOOC design included as a final module two production activities: designing a teaching activity (or Project Work, hereafter PW) using specific software and reviewing (or Peer Review, hereafter PR) a project designed by a colleague. For all those who took part in all MOOC stages (that is, accomplishing all tasks for collecting all weekly badges and accomplishing the PW and PR), a participation certificate was issued by the Mathematics Department of the University of Turin.

\subsubsection{Collaborative ways of working and their conception}

Collaboration among the trainees (both small groups and the whole group) is made possible through the platform and the communication boards provided (for more details see: Taranto et al., 2017). Trainees are engaged in discussions on didactics, activities, classroom experiments, and formative assessment (the PR that each trainee has to do). On the other hand, the collaboration among the trainers takes place both during the design and during the monitoring stages of the MOOC. The experience of monitoring trainees' discussions on the communication boards and the feedback received through questionnaires filled in by trainees were certainly taken into account to make

9 Retrieved October 25, 2017 from http://www.katyjordan.com/MOOCproject.html 
courses evolve from one season to another. It is on the analysis of the design principles and the assessment choices made by the trainers that we will focus in the following.

\section{3. eFAN Maths, the French MOOC (seasons 2 and 3)}

\subsubsection{Initiation, foci and aims of collaboration}

In autumn 2015, at the French Institute of Education (Ifé) of the Ecole Normale Supérieure in Lyon, a team of researchers and teachers had the idea to take up and re-adapt some contents of the first season of the eFAN Maths MOOC ${ }^{10}$ delivered in 2014. It was so possible to preserve the aim of the MOOC, namely fostering mathematics teachers' professional development with the use of technology for teaching and training mathematics, especially at secondary school. The MOOC is in line with the Stratégie Mathématiques program of the French Ministry of Education, which stresses the relationship of mathematics with other sciences and with the world, and aims at training teachers in this perspective in order to give students a refreshed image of mathematics. More specifically, the second season of the MOOC was designed with a double institutional aim: to support teachers and teacher educators in understanding and implementing new aspects of the French curriculum ${ }^{11}$ applicable since September 2016 in all French primary and secondary schools, namely computational reasoning and interdisciplinary work, and to promote collaboration within the French-speaking community all over the world. The MOOC experience offered to teachers a possibility to collaborate in small groups within a wider online community, with a goal of making these groups evolve into lasting communities of practice (Wenger, 1998).

\subsubsection{Scale of collaboration (number of teachers and timeline)}

Three seasons of the eFAN Maths MOOC were delivered: in 2015, 2016 and 2017 respectively. In this chapter, we draw on data from the latter two experiences. The MOOC is delivered on a French national platform (FUN, France Universités Numérique ${ }^{12}$ ) and only free open-source tools are suggested, so that enrolled teachers could easily find and appropriate them. The second and the third seasons of the MOOC delivered essentially the same content, with some differences in the dynamics that we will discuss farther in this chapter. The number of participants was 2572 in the second season and 2690 in the third one. They were mostly French-speaking mathematics teachers and teacher educators interested in the use of technology. The second season was organized in five weeks, from February to mid-March 2016, while the third one, from February to the end of March 2017, added two central weeks for facilitating group work. The percentage of participants who completed all of the proposed activities was about $12 \%$ in the second season, which is comparable with the current average completion rate reported in literature (15\%, see above $\S 2.2 .2)$; this percentage decreased in the third season of the MOOC to $6 \%$ (see comments to Tables 2 and conclusion for possible interpretations).

\subsubsection{Composition of collaborative groups and participants' roles}

The trainers' team was composed of researchers in Mathematics Education from France as well as from Senegal and Cameroon, and mathematics secondary teachers involved in research at the Ifé. Their role was to design and deliver courses and to monitor trainees' activities. Since the delivered content was the same, the trainees were generally different from one season to another. They were encouraged to play an active role in designing and analyzing a mathematical task integrating the use

\footnotetext{
10 Enseigner et Former avec le Numérique en Mathématiques (Teaching and training mathematics with technology), https://www.fun-mooc.fr/courses/ENSDeLyon/14003S03/session03/about

11 French curriculum and supporting material are available at http://eduscol.education.fr/

12 https://www.fun-mooc.fr/courses/ENSDeLyon/14003S03/session03/about
}

Springer book 
of a digital tool and, week after week, the proposed activities aimed to support trainees in their work. Each of the five weeks of the MOOC proposed three video-lessons on key concepts related to technology in mathematics education, MCQs, an activity related to the theme of the week and a few articles for an in-depth study. The examples discussed in the video-lessons were selected and adapted from different European research projects (e.g., FaSMEd ${ }^{13}$, MC Squared ${ }^{14}$ ) with a focus on the use of technology supporting formative assessment and enhancing creative mathematical thinking.

The designers provided an open environment to encourage trainees' participation. Some trainers worked as community managers: they helped trainees to solve technical problems; made tutorials; created and regularly updated a list with all the trainees' ongoing projects to help teachers to find a project to join; they recalled the tasks to be done week by week. Furthermore, every week began with a short video titled "From one week to another" in order to bridge two consecutive weeks of the MOOC.

\subsubsection{Collaborative ways of working and their conception}

To encourage collaboration, trainees were invited to work on the proposed activities in a collaborative way, by forming groups around common interests in a mathematical theme on Viaéduc ${ }^{15}$, which is a professional social network for teachers that essentially allows members to post comments, to create groups, to create and publish documents and to comment or recommend or share them. Group members can work collaboratively either asynchronously, being authors of the same online document, or synchronously, writing on the same online collaborative board (padlet). To cultivate and trigger the formation of trainees' groups as communities of practice, one trainer per group followed the development of the group project from within, intervening to encourage and trigger collaborative work (Panero et al., 2017). The project, elaborated collaboratively, went through two phases of assessment: a peer assessment with the possibility of improving the work taking into account the received feedback, and a trainers' assessment (by the trainer who followed the group all along the MOOC).

In what follows we focus on the analysis of the design principles and the assessment choices made by the trainers.

\subsection{Research questions}

The research questions that guided our study were:

(i) What design issues emerge when trainers aim at mediating at distance teachers' professional development courses with technology?

(ii) How to assess the impact of such courses on mathematics teachers' engagement?

While searching for answers to these questions, we aim not only to highlight relevant designs for teacher professional development programs on the one hand, and their impact on teachers' engagement on the other, but also to gain insights on possible links and consequences of one over the other. The collaboration of the teachers involved in such MOOCs is a consequence of the design of activities that encourage participants to collaborate at large scale and with different modalities.

\footnotetext{
13 Formative Assessment in Science and Mathematics Education (fp7/2007-2013 grant agreement n.612337).

$14 \quad$ Mathematical Creativity Squared (ICT-2013.8.1 "A Computational Environment to Stimulate and Enhance Creative Designs for Mathematical Creativity”, Project 610467).

15 http://www.viaeduc.fr
} 
Collaborative work is also a step towards learning different kinds of knowledge in different contexts (Robutti et al., 2016). Thus, in what follows, we focus on the design principles and assessment strategies that - as trainers - we use in our MOOCs. We hope that the reader will gain benefit from our expertise with online educational environments such as MOOCs.

\section{THEORETICAL FRAMEWORK}

The theoretical elements used independently by both trainer-researchers' teams in Italy and in France are the notion of the communities of practice (Wenger 1998) and the theory of the MetaDidactical Transposition (MDT; Arzarello et al. 2014). Therefore, when the two teams exchanged on their respective experiences with MOOCs for mathematics teacher education, these theoretical elements emerged as a common global frame. They allow us to describe and analyze practices of the two MOOC communities (trainers and trainees) and their evolution over time when the two communities interact.

The MDT model is grounded in the Anthropological Theory of the Didactics (ATD, Chevallard 1999), borrowing and extending the notions of praxeology and of didactical transposition. More specifically, trainers and trainees develop each their own praxeologies to solve specific types of task. Given a type of task, we can identify the related praxeology, which is composed of a practical part (techniques to solve tasks of the given type) and a theoretical one (the logos justifying the used techniques). The MDT model distinguishes between didactical and meta-didactical praxeologies. The didactical praxeologies aim to model the mathematical activity when solving a didactical task, such as "to teach a particular mathematical topic". The meta-didactical praxeologies concern metadidactical tasks, such as "to reflect on possible praxeologies for teaching that particular concept". Concretely, trainers' praxeologies are meta-didactical in the sense that they deal with a discourse about the didactical issues given as tasks to the trainees, who from their side, have their own didactical praxeologies. The two types of praxeologies, namely trainers' and trainees' ones, can initially differ: some of their components can be internal to one community but external to the other. Thanks to the interactions of the two communities they can evolve from external to internal (internalization process, Arzarello et al. 2014, p. 9-10).

More specifically, this chapter focuses on the trainers' meta-didactical praxeologies related to crucial tasks of teacher education within MOOCs.

Adapting the MDT model to MOOCs, Taranto et al. (2017) notice that in these online environments trainers and trainees are led to solve tasks using multiple procedures or multi-procedures, which we call - with the intent of extending the ATD language - "multi-techniques". They are multiple procedures because if one considers only one of them individually, the task cannot be solved in a satisfactory manner. Instead, as we will see in the analysis section, a fair number of them need to be considered. Note, however, that it may be inaccurate to talk about techniques since what follows will be a list of suggested procedures that we want to share with other potential MOOC trainers in teacher education. The procedures will in fact become techniques once they will be universally shared and institutionally recognized (Chevallard, 1999) by the research community.

In our study, we analyse the trainers' praxeologies that can be considered as meta-didactical in the sense that they deal with a discourse about didactical issues: hence we identify the meta-didactical praxeologies by selecting the tasks that are essential for the design of a MOOC. These tasks concern both the design principles and the assessment strategies. Through the analysis of the praxeologies associated to these tasks, we will catch several essential topics regarding MOOCs: (i) the relationship between design principles and professional development that can be grasped through the audience of each of the MOOC (see Table 1); (ii) the theme(s) of the MOOC, which is(are) 
essential from an institutional point of view (see Table 2); (iii) the delicate question of the relationships between trainees and trainers (see Tables 3 and 4); (iv) the assessment strategies included in the MOOC design, which gives important clues to assess trainees' engagement (see Tables 5, 6, 7).

\section{METHODOLOGY}

Drawing on the MDT, we pointed out some essential meta-didactical types of tasks that, according to our experiences, any trainer of a MOOC for mathematics teacher education should address. Precisely, we consider four topics related to the design principles: Target, Theme, Trainers' interaction with trainees, Collaboration among trainees. Moreover, we take into account three topics related to the assessment strategies: Test, Project Work, Peer Review. For each topic, we describe the Italian and the French meta-didactical praxeologies. In fact, we identify the related meta-didactical types of tasks, the techniques adopted by trainers in the Italian Geometria MOOC and in the French eFAN Maths MOOC respectively, to solve such tasks, as well as the related justification (logos). For the logos, we particularly wondered how the chosen techniques were justified and supported by theories in Mathematics Education or more generally in the educational field. The Italian and the French praxeologies may not coincide because of the different nature of the MOOCs (e.g. institutional context) but they will be similar in their purpose.

The identification of these meta-didactical praxeologies has been possible by reflecting on the design phases in which we were involved both in the first and the second season of our MOOCs; but also on the massive assessment phases. In particular, we analyzed the evolution of the trainers' meta-didactical praxeologies to design the subsequent season of the respective MOOCs (Numeri MOOC and season 3 of the eFAN Maths MOOC). The reasons for this evolution (intended as an improvement of the professional development program) came from the trainers' self-analysis of the respective experiences but also from some trainees' comments (via questionnaires or posts in communication message boards). In the following section, we focus on these aspects, also highlighting similarities and differences between our online educational experiences.

\section{ANALYSIS}

\subsection{Design principles}

The analysis reported in this section is driven by our first research question:

What design issues emerge when trainers aim at mediating at distance teachers' professional development courses with technology?

Both the Italian and the French MOOCs aim at professional learning and raising awareness of the possibilities for technology use in schools. Given this aim, it is important to identify a hypothetical target trainee: who could be the teachers that can benefit from this educational massive open online course? However, MOOC designers cannot know in advance the teachers who will decide to enroll in the MOOC and they will never meet them in person. For these reasons, as trainers, "you are forced to hypothesize a mean Zone of Proximal Development (ZPD) of your future trainees" (Taranto, in preparation). The ZPD (Vygotsky, 1978) concerns an internal level and comes into play when the trainers think about the ideal didactical praxeologies that they want to transpose to trainee teachers who will follow the MOOC. Therefore, as Taranto (ibid.) notices, trainers assume a certain level of prior knowledge (ZPD) of the trainees' community (not of the individual teacher since they are forced to consider mean values). They prepare and administer certain activities in order to help the trainees' community to move from the current level (their present didactical praxeologies) to the potential level (the ideal didactical praxeologies). 
The current level of the trainees' community can be recognized in what Goos (2013) lists to describe the teacher's ZPD. Precisely, it includes the professional development level of the traineeteachers in terms of: mathematical knowledge; pedagogical content knowledge; skill/experience in working with technology; as well as, beliefs about mathematics, teaching and learning (Goos, 2013, p. 524). Such current level of professional development could evolve thanks to the contents the trainees find in the MOOC. The MOOC contents are carefully designed and implemented by trainers and they are related to specific mathematics topics or important themes of the curricula.

Regarding the topic "Target" (Table 1) there has not been any evolution from a MOOC season to another. The target was clearly stated and, since the enrolled participants proved to be in line with our expectations, no changes were needed.

\begin{tabular}{|l|l|l|}
\hline \multicolumn{1}{|c|}{$(\mathbf{1 )}$} & \multicolumn{2}{|c|}{ Target } \\
\hline Task & Italian MOOC & French MOOC \\
\hline $\begin{array}{l}\text { to identify a hypothetical target trainee } \\
\text { (lower and higher secondary school } \\
\text { teachers) }\end{array}$ & $\begin{array}{l}\text { to identify a hypothetical target trainee } \\
\text { (lower secondary school teachers) }\end{array}$ \\
\hline Technique & $\begin{array}{l}\text { to choose activities of a specific school } \\
\text { level (according to the target), related to } \\
\text { specific mathematics topics }\end{array}$ & $\begin{array}{l}\text { to design activities for this specific target, } \\
\text { related to important themes of the curricula }\end{array}$ \\
\hline Logos & \multicolumn{1}{|c|}{ to hypothesize a mean ZPD of the future trainees } \\
\hline Evolution & \multicolumn{2}{|c|}{ None } \\
\hline
\end{tabular}

Another essential aspect of a MOOC design for mathematics teacher education is the "Theme" (Table 2). To this purpose, the trainers face two types of tasks and for each they can adopt different multi-techniques.

The choice of the theme is naturally related to the identified target and to institutional purposes of the professional development program. Both MOOCs aim to respond to specific teachers' needs identified in the institutional and social contexts, referring to national plans for teacher professional development and to crucial (or even new, in the French case) aspects of the national curriculum.

Designers have to evaluate essentially two possibilities, according to their long-term educational aim: to change the MOOC theme from season to season trying to cover one by one different crucial aspects and educational objectives; or to keep the same theme and deliver the same content, considered as crucial in the professional development, in every season. Such a decision influences the potential MOOC audience. Indeed, with the former choice, as in the Italian case, the same group of teachers can enroll into every season of the MOOC to pursue their professional development; with the latter choice, as in the French case, the opportunity of professional development is offered to an increasing group of teachers (including those who have not completed the previous season).

Once the theme and its possible evolution from season to season are decided, designers have to consider the time variable. The Italian and French experiences highlight again two possible approaches: decide how much time has to be devoted to each module of the MOOC or how much material it is possible to read and work on in a module that has a fixed duration (e.g. one week). The Italian team chose the first approach and, according to the theme, they decided to devote one week or two to the same content or methodology because of its complexity or of the material profusion. The French team chose the second approach and, given the fixed module duration of a week, it designed and adapted the material in such a way that trainees could manage appropriating it. 
In both cases, designers need to make an average of the estimated learning times of the target (Carroll, 1963). After the first season of the Geometria MOOC, the Italian team decided to reduce the quantity of the provided material and to pay a greater attention to differenting the material for different school levels. The French team instead has not changed its praxeology. Indeed, although trainees complained about the amount of time needed to complete reading of the provided material on FUN, the reason was not the quantity of the material but rather managing the work between following courses on FUN and working on projects on Viaéduc (see Table 6).

\begin{tabular}{|c|c|c|}
\hline (2) & \multicolumn{2}{|c|}{ Theme } \\
\hline & Italian MOOC & French MOOC \\
\hline Task 1 & \multicolumn{2}{|c|}{ to identify the main theme to address in the MOOC } \\
\hline $\begin{array}{l}\text { Technique } \\
\mathrm{s}\end{array}$ & $\begin{array}{l}\text { to focus every season on a different core } \\
\text { part of the curriculum (Geometry, } \\
\text { Number) and to choose activities around } \\
\text { specific topics according to the theme }\end{array}$ & $\begin{array}{l}\text { to focus every season on the same theme } \\
\text { (teaching and training in mathematics with } \\
\text { technology) and to choose activities around } \\
\text { specific topics according to the theme }\end{array}$ \\
\hline Logos & $\begin{array}{l}\text { to innovate methodology and strategies } \\
\text { of teaching mathematics as highlighted in } \\
\text { the Piano nazionale per la formazione } \\
\text { docenti and the Italian curriculum } \\
\left(\text { Indicazioni nazionali }{ }^{16} \text { ). }\right.\end{array}$ & $\begin{array}{l}\text { to renew the vision of mathematics as } \\
\text { highlighted in the Ministry plan of } \\
\text { Stratégie Mathématiques and the French } \\
\text { curriculum (Programmes: see Note 11) }\end{array}$ \\
\hline \multirow[t]{2}{*}{ Evolution } & $\begin{array}{l}\text { The first season was devoted to } \\
\text { Geometry, while the second one to } \\
\text { Numbers. Once a topic is covered (see } \S \\
2.2 .2 \text { ), the professional development } \\
\text { program moves on to another one, with } \\
\text { the long-term aim of deepening the } \\
\text { professional development of the same } \\
\text { group of teachers. } 50 \% \text { of enrolled in the } \\
\text { second season came from the previous } \\
\text { one. }\end{array}$ & None \\
\hline & \multicolumn{2}{|c|}{ Time } \\
\hline Task 2 & $\begin{array}{l}\text { to decide how much time is devoted to } \\
\text { each module of the MOOC }\end{array}$ & $\begin{array}{l}\text { to decide how much material it is possible } \\
\text { to read/work on in a week (fixed duration } \\
\text { of a module) }\end{array}$ \\
\hline $\begin{array}{l}\text { Technique } \\
\mathrm{s}\end{array}$ & $\begin{array}{l}\text { to estimate the time necessary to acquire } \\
\text { the treated topic, taking into account an } \\
\text { estimated engagement of } 4 \mathrm{~h} \text { per week: } \\
\text { - if necessary, to divide theoretical and } \\
\text { practical parts; } \\
\text { - if the material is too dense, to devote } \\
\text { two weeks to the same topic; }\end{array}$ & $\begin{array}{l}\text { to create materials (three videos, related } \\
\text { quiz, activity) in such a way that } 4 \mathrm{~h} \\
\text { (estimate per week) are enough to } \\
\text { appropriate and make use of them. }\end{array}$ \\
\hline Logos & \multicolumn{2}{|c|}{ average of estimated learning times of the target } \\
\hline Evolution & $\begin{array}{l}\text { to reduce the quantity of the material } \\
\text { provided; greater attention to } \\
\text { differentiating the material for different }\end{array}$ & None \\
\hline
\end{tabular}

16 Link to the Italian curriculum:

http://www.indire.it/lucabas/lkmw_file/licei2010/indicazioni_nuovo_impaginato/_decreto_indicazioni_nazionali.pdf

Springer book 


\section{school levels.}

Table 2 - The meta-didactical praxeology related to "Theme"

To make the online interaction with the trainees possible, the trainers are called to put into action some multi-techniques. The first kind of interaction is reading of available materials and didactical resources. Digital resources replace the voice and explanations of the trainers that are usually done in face-to-face courses: so the trainees interact with videos, images, interactive texts. In this way trainers are able to communicate their training intentions at distance, share research results, methodologies and teaching strategies that can be used in class with students. In the Italian MOOCs the activities have been transposed into a digital format according to the E-tivity framework (Salmon, 2013). The E-tivities are designed before opening the MOOC to participants. They support learners in achieving the learning outcomes: in fact, they promote a learner-centred task and problem-based approach to online learning.

Based on the 7Cs of learning design (Conole, 2014), and in particular "Capture ${ }^{17 "}$ and "Communication" 18 ", as well as on the pillars of the "pedagogical contract" and of the "trainer as a facilitator" in the accompanied auto-education (Carrè, 2003), the Italian and French trainers created institutional mail addresses to send e-mails periodically in order to have moments of direct contact with the group and/or with the individual trainees. Precisely, weekly mails were sent to all members to remember the content and required activities, and private emails or specific forums were set up for technical issues. The French team also created video summaries of weekly activities and performance.

The French team decided that one trainer per group of trainees would follow the development of the work from within, by becoming the group member, encouraging collaborative work and helping the group turning into a community of practice. The Italian team, instead, preferred to alternate the platform control moments, managed by groups of teacher-designers per module, with synchronous contact moments through webinars. These are online meetings in which an expert (seen through a camera) shares with the trainees (who can only interact via chat) some issues about the research in mathematics education and focuses on some questions that could be raised during the previous weeks in the MOOC.

Questionnaires were administered for a feedback on the degree of appreciation of the educational offer. The Italian team has administered 3 questionnaires (at the beginning, at halfway of the course, at the end); the French team one at the end. Meetings with some of the French trainees were organized at the end of the MOOC, which allowed the French trainers to gather more explanatory answers. From the feedback they received, both teams understood how to better refine some questions to get clearer information. Moreover, the French team decided to announce the questionnaire from the beginning of the MOOC in order to reach trainees who would drop out of the MOOC before its end.

\begin{tabular}{|l|l|l|}
\hline \multicolumn{1}{|c|}{$(\mathbf{3})$} & \multicolumn{2}{c|}{ Trainers' } \\
\hline & Italianteraction MOOC & \multicolumn{1}{c|}{ French MOOC } \\
\hline Task & \multicolumn{2}{c|}{ to make the interaction WITH the trainees possible } \\
\hline
\end{tabular}

17 In terms of capturing resources to be used: What resources are being used and what other resources need to be developed? (Conole, 2014, pp. 1, 3)

18 Mechanisms to foster communication: How are the learners interacting with each other and their tutors? (Conole, 2014, pp. 3-4) 


\begin{tabular}{|c|c|c|}
\hline Techniques & $\begin{array}{l}\text { - to transpose in a digital format } \\
\text { materials and didactical resources for } \\
\text { teacher education } \\
\text { - to create institutional e-mail } \\
\text { addresses for sending periodic e- } \\
\text { mails (e.g. weekly e-mail, private e- } \\
\text { mail for technical problems) } \\
\text { - to open forums for technical and } \\
\text { didactical issues } \\
\text { - to organize webinars for creating } \\
\text { occasions of synchronous contact } \\
\text { - to prepare and administrate } \\
\text { questionnaires }\end{array}$ & $\begin{array}{l}\text { - to transpose in a digital format materials } \\
\text { and didactical resources for teacher } \\
\text { education } \\
\text { - } \text { to send an e-mail, at the beginning of } \\
\text { the week, to all members as a reminder } \\
\text { of the activities to be done, and private } \\
\text { emails or specific forums on FUN for } \\
\text { technical problems } \\
\text { - to create videos "from one week to } \\
\text { another" as the first content of the new } \\
\text { module } \\
\text { - to prepare and administrate the final } \\
\text { questionnaire } \\
\text { - to evaluate the MOOC face-to-face with } \\
\text { some trainees (the most active ones) at } \\
\text { the end of the experience } \\
\text { - to follow the development of the group } \\
\text { work on Viaéduc (one trainer per } \\
\text { group) }\end{array}$ \\
\hline Logos & $\begin{array}{l}\text { E-tivity framework for digital } \\
\text { transposition; } \\
\text { "Capture" and "Communicate" from the } \\
\text { 7Cs }\end{array}$ & $\begin{array}{l}\text { "Pedagogical contract" between trainers } \\
\text { and trainees and the role of the "trainer as a } \\
\text { facilitator" as pillars of the accompanied } \\
\text { auto-education }\end{array}$ \\
\hline Evolution & $\begin{array}{l}\text { some questions in the questionnaires } \\
\text { have been changed }\end{array}$ & $\begin{array}{l}\text { some questions in the questionnaires have } \\
\text { been changed and a questionnaire has been } \\
\text { announced from the first weeks of the } \\
\text { MOOC }\end{array}$ \\
\hline
\end{tabular}

Table 3 - The meta-didactical praxeology related to "Trainers' interaction with trainees"

Fostering collaboration among trainees (Table 4) is not a peculiarity of all MOOCs, but we stated since the beginning that it is a fundamental aspect common to the Italian and the French MOOCs, distinguishing them from other kinds of online courses where the trainee alone has to watch videos and accomplish activities. We conceive our MOOCs as authentic collaborative experiences and for this reason we described them above $(\S 2)$ in terms of the four dimensions of the collaborative work. However, collaboration cannot be considered as spontaneous way of work, especially within such remote contexts. Designers have to make it possible through specific multi-techniques. The Italian and the French praxeologies related to this task constitute some effective examples of how to solve it. In both cases, the trainers' teams provide an "open environment" (Carré, 2003) and ground their choices on "Collaborate" in the sense of Conole (2014). The French team opted for a professional social network with integrated collaborative tools: a careful coordination of the two platforms (FUN for the courses and Viaéduc for the collaborative projects) is extremely important to support the trainees in finding their bearings between the two online workspaces. The Italian team used forums provided by DI.FI.MA. platform, where the courses were delivered, and decided to add some collaborative tools such as Padlet and Tricider from the outside. In both cases, the trainers felt the need to augment the "official" platform with additional tools to properly foster collaboration. This fact is relevant for us and can be interpreted as the current lack of remote platforms for online courses, which can fully support collaboration among participants. We will discuss this point further in the conclusion. 
In the forums, both teams adopted a technique to initiate discussions with a prompting question in order to accompany trainees in reading the materials and identifying their focus. As a difference between the meta-didactical praxeologies of the trainers of the two MOOCs, we can identify the influence of a technique used for interacting with the trainees, that is how and how much to intervene in the trainees' work. It turned out that the Italian team is focused on global collaboration, fostering it within the entire community of the MOOC and aiming at the creation of a global community of practice made only by trainees (Taranto et al. 2017). The French team, instead, is focused on local collaboration, fostering it within small groups of the MOOC community and aiming at the creation of small local communities of practice around a common project, where the trainer intervenes and acts as a tutor before and as an assessor in the end (Panero et al. 2017).

\begin{tabular}{|c|c|c|}
\hline (4) & \multicolumn{2}{|c|}{ Collaboration among trainees } \\
\hline & Italian MOOC & French MOOC \\
\hline Task & \multicolumn{2}{|c|}{ to make the interaction AMONG trainees possible } \\
\hline Techniques & $\begin{array}{l}\text { - to provide a suitable space for making } \\
\text { the remote communication possible } \\
\text { (communication message boards such as } \\
\text { forum, padlet, tricider) } \\
\text { - to initiate discussions on forums with a } \\
\text { prompting question (in order to } \\
\text { accompany trainees in reading the } \\
\text { materials and identifying their focus) } \\
\text { - to reduce trainers interventions, } \\
\text { monitoring behind the scene }\end{array}$ & $\begin{array}{l}\text { - to open a collaborative workspace on } \\
\text { Viaéduc for making the remote } \\
\text { communication possible } \\
\text { - to initiate discussions on forums with a } \\
\text { prompting question (in order to accompany } \\
\text { trainees in reading the materials and } \\
\text { identifying their focus) } \\
\text { - to foster collaboration from the inside } \\
\text { (one trainer per group) }\end{array}$ \\
\hline Logos & $\begin{array}{l}\text { "Collaborate" in the } 7 \mathrm{Cs} \text {; to foster the } \\
\text { birth of a community of practice }\end{array}$ & $\begin{array}{l}\text { The presence of an "open environment" } \\
\text { among the pillars of Carré's model; to } \\
\text { foster the birth of small communities of } \\
\text { practice }\end{array}$ \\
\hline Evolution & $\begin{array}{l}\text { to provide more tutorials to allow } \\
\text { trainees to move autonomously in the } \\
\text { collaborative space and to use } \\
\text { collaborative tools as efficiently as } \\
\text { possible. }\end{array}$ & None \\
\hline
\end{tabular}

Table 4 - The meta-didactical praxeology related to "Collaboration among trainees"

\subsection{Methodological choices based on design principles for assessment}

In this section, we address the second research question:

How to assess the impact of such courses on mathematics teachers' engagement?

The massiveness makes it very difficult to personally follow every participant. In Table 3 we stated that we were always vigilant, with private emails, through a group trainer in the French team or more trainers per module in the Italian team, to follow the development of the work from within. But, how one might get immediate understanding of the progress that each trainee does?

Both teams introduced weekly test to understand the trainees' appropriation of the video content and module activities. The tests consisted in MCQs (Table 5) allowing up to 2 (in the French case) or 3 (in the Italian one) attempts: in fact, we gave feedback about the given answer (Velan et al., 
2008). The trainees could go through reviewing the resources and trying to find the correct answer. Correct answers indicated that the resources had been explored in depth and not superficially. Additionally, granting multiple attempts was a guarantee of success for trainees.

In the Geometria MOOC, the trainees did not share the same opinion about the tests: they saw the test as an overload of work besides the commitment already required by the MOOC on a weekly basis. Therefore, tests have been removed from the second season (Numeri MOOC). The French trainees did not complain about the tests. Therefore, there is no evolution regarding the technique of MCQs because this technique is required by the institution (FUN) in order to provide a certificate of attendance. However, there is an evolution regarding the MCQs.

Another technique that remained unchanged in the Italian MOOCs is the end module badge. It was obtained if the trainee self-declared to have seen some specific resources, if she wrote on the communication message boards when required and if she uploaded specific materials when asked. Once all the module requests were accomplished (test included), the platform released the badge (Figure 1). In this way, it was quite easy for the Italian team to monitor the progress of the trainees, knowing the amount of badges they had collected.

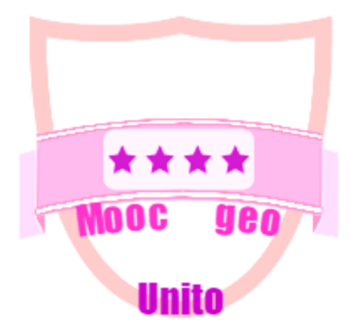

Figure 1: Badge of Module 4 in the Geometria MOOC

\begin{tabular}{|l|l|l|}
\hline \multicolumn{1}{|c|}{$(\mathbf{5 )}$} & \multicolumn{2}{|c|}{ Test } \\
\hline & Italian MOOC & \multicolumn{2}{|c|}{ French MOOC } \\
\hline Task & \multicolumn{1}{|c|}{ to assess the degree of participation of the trainees weekly } \\
\hline Techniques & $\begin{array}{l}\text { Multiple Choice Test with up to 3 } \\
\text { attempts related to the video content } \\
\text { and module activities } \\
\text { release of the badge (the test was a } \\
\text { necessary and sufficient condition } \\
\text { for its release) }\end{array}$ & $\begin{array}{l}\text { Multiple Choice Test with up to } 2 \\
\text { attempts related to the video content and } \\
\text { module activities }\end{array}$ \\
\hline Logos & $\begin{array}{l}|c| \\
\text { Evolution }\end{array}$ & $\begin{array}{l}\text { Test was present in the first season, but } \\
\text { removed from the second one }\end{array}$ \\
\hline
\end{tabular}

Table 5 - The meta-didactical praxeology related to "Test"

Both the Italian and the French teams chose a project-based methodology (Bender, 2012) to assess the trainees' engagement, but articulated it in different ways, and both turned out to be efficient (Table 6).

The project consisted in designing a classroom activity: by describing and analyzing a priori its potential for the learning of mathematics, trainees had to demonstrate acquired teaching competencies and expertise. In fact, the project-based methodology has been chosen to give trainees the opportunity to get involved in the MOOC activities in terms of methodology, creativity, and with the aim of sharing and discussing them in the community: the entire MOOC community in the Italian case, or their own small collaborative group in the French case. Indeed, Italian trainees had 
to produce an individual Project Work (PW), while French trainees a collective one. They were free to choose the theme of their project: in the Italian case, a geometric theme, while in the French case, any mathematical theme involving technology. A big difference between the trainers' praxeologies can be found in the instructions given to trainees for carrying out the PW. The Italian team gave a lot of freedom to trainees: trainers did not want neither to influence them nor to restrain their creativity. Trainees had to use a web-based tool, the Learning Designer (hereafter LD) designed by Laurillard (2016). LD is a software that guides and encourages planning of a lesson: it is characterized by a standard format that allows to integrate technologies, to have an overview of the teaching/learning dynamics centered on the student and to share online what the teacher has produced. The French group projects have to be collaboratively written on Viaéduc, using its integrated tools. French trainers gave to trainees clear instructions and guidelines to carry out their PW: for each phase of the PW, corresponding to each week activity, description and analysis grids were provided. They consisted in guiding questions grounded in the instrumental approach (Rabardel, 1995) and in the instrumental orchestration (Trouche, 2004). Moreover, a fictive group was created among the real ones in order to give trainees possible examples of the expected activities.

Both trainers' techniques include the creation of video and pdf tutorials in order to familiarize the trainees with LD on the one hand, and with collaborative tools of Viaéduc on the other hand. In the Geometria MOOC, these tutorials were available two weeks before the opening of the last module while in the eFAN Maths MOOC they were available since the beginning of the MOOC because the PW was carried out all along the MOOC experience. Furthermore, deadlines for accomplishing the PW were announced as sharp because trainers wanted to allow everyone to do a Peer Review (see Table 7). However, some trainees expressed the need to have more time to accomplish their PW. Thus, in both subsequent seasons of the MOOCs the deadline was extended by 2 weeks. Moreover, the French team decided to leave PWs of the previous season available on Viaéduc.

\begin{tabular}{|c|c|c|}
\hline (6) & \multicolumn{2}{|c|}{ Project work } \\
\hline & Italian MOOC & French MOOC \\
\hline Task 1 & \multicolumn{2}{|c|}{ to assess the competences acquired through the MOOC } \\
\hline Techniques & $\begin{array}{l}\text { - trainees are asked to carry out an } \\
\text { individual project } \\
\text { - recommendation to use the LD } \\
\text { software } \\
\text { - trainees can choose the content to } \\
\text { address in their project according to the } \\
\text { theme of the MOOC }\end{array}$ & $\begin{array}{l}\text { - trainees are asked to carry out a group } \\
\text { project } \\
\text { - description and analysis grids are } \\
\text { provided } \\
\text { - trainees can choose the content to address } \\
\text { in their project according to the theme of } \\
\text { the MOOC } \\
\text { - to provide a visual organisation of what is } \\
\text { done and what is to be done (framaboard) } \\
\text { for each group and update it frequently. }\end{array}$ \\
\hline Logos & \multicolumn{2}{|c|}{ project-based learning } \\
\hline & \multicolumn{2}{|c|}{ Time } \\
\hline Task 2 & $\begin{array}{l}\text { to decide how much time is devoted to } \\
\text { the individual project work }\end{array}$ & $\begin{array}{l}\text { to decide how much time is devoted to the } \\
\text { group project work }\end{array}$ \\
\hline Techniques & $\begin{array}{l}\text { to estimate the time necessary to carry } \\
\text { out the individual project (one week); to } \\
\text { give instructions/tutorials about LD } \\
\text { starting from the week before }\end{array}$ & $\begin{array}{l}\text { to estimate the time necessary for sharing } \\
\text { ideas in the group and carrying out the } \\
\text { project (all along the MOOC); to give } \\
\text { instructions/tutorials on Viaéduc starting }\end{array}$ \\
\hline
\end{tabular}




\begin{tabular}{|l|l|l|}
\hline Logos & $\begin{array}{l}\text { fhe time for appropriation of an artefact } \\
\text { as LD }\end{array}$ & $\begin{array}{l}\text { fultivation of small communities of } \\
\text { practice requires time; time for } \\
\text { appropriation of the artefacts of Viaéduc }\end{array}$ \\
\hline \hline Evolution & $\begin{array}{l}\text { the deadline to carry out the project } \\
\text { work was extended by 2 weeks }\end{array}$ & $\begin{array}{l}\text { the deadline was extended by 2 weeks; PW } \\
\text { of the previous season were left as } \\
\text { examples on Viaéduc }\end{array}$ \\
\hline
\end{tabular}

Table 6 - The meta-didactical praxeology related to "Project work"

To stimulate collaboration among trainees and to foster formative assessment among peers (Black \& Wiliam, 2009), both teams proposed a Peer Review (PR) activity (Table 7). As for the PW, for the PR the trainers have to face two tasks and for each they can adopt different multi-techniques.

In the Italian case, it was a 1 by 1 peer review: each trainee had to review a colleague's PW from an educational point of view, without any marking intention. The teachers were divided, thanks to an excel table, taking into account their school level. In the excel table each trainee found the PWs title and links to LD to facilitate spotting of the PW to review. The instructions for the PR were given in a more specific way compared with the PW. In the week dedicated to the PR, a revision grid containing the review criteria was given: attention to the main aspects of each educational intervention and to a conscious use of digital software. The grid provides 5 categories: Connections to the real world; Creativity; Collaboration; Use of technology; General considerations. For each of these categories, some features are indicated. They are to be evaluated by using a scale from 1 (= little present aspect) to 5 (= highly present aspect). The final request was to leave a comment highlighting the strengths of the project, the parts that could be improved and possible reviewer's curiosities. The Italian team gave one week to accomplish this task, considering this as a suitable time for internalizing (Arzarello et al., 2014, p. 9-10) the criteria of assessment.

Also in this case, in the forum dedicated to technical problems, some trainees expressed the need of having more time available for accomplishing their PR and also to receive in advance the criteria to better accomplish the design task of the PW. In the subsequent season of the MOOC, the deadline for accomplishing the PR was extended from one to two weeks. Moreover, the revision grid was given at the beginning of the two weeks of PW (i.e., two weeks before the start of the revision process). In addition, the project to be reviewed was assigned by the trainers to each trainee taking into account the school level. This choice was done because in the previous season more than one trainee selected the same PW and some PW remained without a reviewer. In both seasons the PRs were delivered on the platform and made available to each trainee.

In the French case, the projects, written collaboratively, went through two phases of evaluation: a peer evaluation with the possibility of improving the work based on the received feedback, and a trainers' evaluation (by the trainer who followed the group from within). For the first phase, trainees were asked to do an individual peer review of the version 0 of the project of one or more groups of their choice. In particular, an excel table was provided to present the versions 0 of the group projects (with links to pdf and Viaéduc). The evaluation grid was elaborated by the trainers to encompass all the phases of the project developed in the MOOC week after week. This grid was structured around the following four criteria: 1) Accuracy of the definition and description of the project; 2) Relevance of the mobilised digital tools and resources with respect to the educational goals of the designed mathematical task; 3) Relevance of the analysis of the students' expected mathematical activity; 4) Relevance of the analysis of the teacher's role. For each criterion, some guiding questions were proposed with a double objective: to foster the production of justified 
feedback and to deepen the reflection carried out in the previous weeks of the MOOC. The grid finally asked for a brief global feedback on the project and some suggestions to improve the work. Each trainee was invited to use the grid individually to evaluate a project of another group, by answering each guiding question with an evaluation: very good, satisfactory, fragile or insufficient, accompanied by a justification. The community managers gradually collected feedback and comments in a table and shared it in a specific space on Viaéduc

\begin{tabular}{|c|c|c|}
\hline (7) & \multicolumn{2}{|c|}{ Peer Review } \\
\hline & Italian MOOC & French MOOC \\
\hline Task 1 & to review the PW & to review the group project \\
\hline Techniques & $\begin{array}{l}\text { - trainees are asked to do a peer review } \\
\text { (1-1) of a project they choose at the } \\
\text { same school level } \\
\text { - an excel table is provided to organize } \\
\text { the finalised PWs (with links to LD) } \\
\text { to facilitate the choice of the } \\
\text { potential reviewers } \\
\text { - revision grid } \\
\text { - PRs (sent as a task on moodle) } \\
\text { shared with all the participants on the } \\
\text { platform }\end{array}$ & $\begin{array}{l}\text { - trainees are asked to do an individual } \\
\text { peer review of the version } 0 \text { of a project } \\
\text { of one or more groups of their choice } \\
\text { - } \text { an excel table is provided to present the } \\
\text { version } 0 \text { of the group projects (with } \\
\text { links to pdf and viaéduc) } \\
\text { - evaluation grid } \\
\text { - collection of feedback via a } \\
\text { questionnaire (google form) and sharing } \\
\text { of the resulting table with the entire } \\
\text { group on viaéduc } \\
\text { - the tutor of each group assesses the } \\
\text { version } 1, \text { revised by the group }\end{array}$ \\
\hline Logos & $\begin{array}{l}\text { stimulate collaboration, peer assessment } \\
\text { (formative assessment), deal with the } \\
\text { massive nature of MOOC }\end{array}$ & $\begin{array}{l}\text { stimulate collaboration, peer assessment } \\
\text { (formative assessment), criteria shared in } \\
\text { the trainers' group to assess versions } 1\end{array}$ \\
\hline & \multicolumn{2}{|c|}{ Time } \\
\hline Task 2 & \multicolumn{2}{|c|}{ to decide how much time is devoted to the peer review } \\
\hline Techniques & $\begin{array}{l}\text { - to estimate the time necessary for } \\
\text { reviewing one colleague's project } \\
\text { (one week) } \\
\text { - provide the revision grid, in the week } \\
\text { of the PR (last module) }\end{array}$ & $\begin{array}{l}\text { - to estimate the time necessary for } \\
\text { reviewing one group's project (one } \\
\text { week) } \\
\text { - provide the evaluation grid, in the week } \\
\text { of the peer review (last week) }\end{array}$ \\
\hline Logos & \multicolumn{2}{|c|}{ time for internalizing the criteria of assessment (MDT) } \\
\hline Evolution & $\begin{array}{l}\text { the deadline to accomplish the PR was } \\
\text { extended and the revision grid was given } \\
\text { at the beginning of the two weeks of } \\
\text { PW. The project to be reviewed was } \\
\text { assigned by the trainers to each trainee } \\
\text { taking into account the school level. }\end{array}$ & None \\
\hline
\end{tabular}

Table 7 - The meta-didactical praxeology related to "Peer Review"

\section{DISCUSSION AND CONCLUSION}

In this chapter, we analysed two seasons of MOOCs aimed at mathematics teacher professional development, designed in France (Lyon) and in Italy (Turin). As pointed out in the Introduction, MOOCs with this aim are rare. Some authors claim that they are a promising tool for such a use, but they generally do not directly address the issue of mathematics professional development: the research on effective teachers' learning processes within such new environments are not so diffuse, 
and those concerning mathematics teachers are de facto missing. Hence, our analysis humbly tries to open a new road on this terrain.

A major starting issue for us was to define a proper theoretical frame for our analysis, which could satisfy two constraints:

The literature is rich in papers concerning the way mathematics teachers can improve their professional knowledge: e.g. Robutti et al. (2016) present a wide survey of this topic, but the related literature generally describes situations where technology concerns mainly how to improve students' learning (at school or at home), not teachers' learning in MOOC courses.

- In MOOCs where teachers are the direct addressees of such online courses, the philosophy behind MOOCs puts at the first place the transformative impact of technology in teaching and learning occurred during the last decade. This focus must be taken in charge specifically by MOOCs designed for (mathematics) teachers' professional development.

The two instances are not contradictory but require a sophisticated analysis tool that can combine these two sides in a complementary, coherent, and productive way. Our task can be expressed through a winegrowers' maxim: "put the new wine in old barrels". Namely, we had to analyse a new way of designing and assessing courses for teachers through MOOCs, using (at least a part of) the old and powerful theoretical lens of the MDT (Arzarello et al., 2014). Our chapter accomplished this task, making it possible to produce a "good wine", apt to the analysis we were faced to; moreover, it made possible a comparison of pros and cons with respect to the two approaches (the Italian and the French ones).

Out of the metaphor, the praxeological analysis of the selected types of tasks, as detailed in Tables from 1 to 7 of section 5, gives significant answers to the research questions. Particularly, regarding the usefulness of design principles, the great importance of the institutional context, which has been taken into account by the two teams, is highlighted as an essential issue of a MOOC design. Also, as pointed out by Bozkurt \& al. (2017): "Findings of this research revealed that the least explored research areas are learner support services; management and organization; access, equity, and ethics" (p.12). Our methodological approach tends to give information about the learner support services through the design choices made by the teams regarding the trainers' interaction with trainees and the assessment of the trainees' work through crossed analysis.

One main similarity between the two MOOCs experiences lies on the methodological choice of the project-based assessment. The model itself of MOOC does not allow researchers to observe directly the effect of the training courses proposed by the MOOCs and to gather feedback from observations in classes. For this reason, both teams considered the PW as a suitable way to assess the competencies acquired by the trainees. The PW was individual in the Italian case, collaborative in the French one, but in both cases a PR was proposed to evaluate the work. The evidence is that the connection between trainees does not go without saying and that the role of tutors as well as their scope of activities must be included in the design principles of MOOCs. Moreover, time to devote to these tasks is an important issue to consider and it was increased in both experiences. On the contrary, leaving the PW carried out in the previous season as inheritance for the next one may inhibit trainees' creativity, as happened in the French case (this could be a reason why the completion rate decreased).

The main differences between the two MOOCs are underlined: often, they are of minor relevance, but sometimes it is not so. For example, see the final part of the comments to Table 4, where an important difference between the forms of trainees collaboration is made apparent through the analysis of the trainers' techniques: global collaboration in the Italian MOOC vs local collaboration 
within the French one. While this result puts forward a sort of inner difference between the two MOOCs experiences, an external difference between our MOOCs and other forms of experiences through the use of platforms (even in different experiences of MOOCs) is made apparent in Table 4: the four dimensions of the collaborative work allow to show the specific involvement of trainees in our MOOC and the form of their active involvement. A main result is that collaboration cannot be considered as a spontaneous way of working, especially within such remote contexts. Designers have to make it possible through specific techniques. The Italian and the French praxeologies related to this task constitute some effective examples of how to solve it. The French team opted for a professional social network Viaéduc to integrate collaborative tools that were missing on the FUN platform. The same necessity was felt by the Italian team using forums provided by DI.FI.MA. platform, but also some collaborative tools such as Padlet and Tricider from the outside. Our analysis shows that a real involvement of trainees in collaborative work needs to be triggered and supported by suitable tools added to the platform. The availability in the platform of tools consonant with the social networks used in everyday life increases the triggering of what Manlove et al. (2006) call co-regulated learning, in the sense that the trainees themselves regulate their tasks and collaboration. Our analysis leaves open the question of which devices are the best for improving active collaboration among the trainees: possibly further research and concrete experimentations will be able to give a more definitive contribution to this crucial issue. What is interesting here is that our analysis centered on collaboration processes through the adaptation of the meta-didactical lens has made possible to grasp this important problem in a clear way. This suggests that the way of research we have undertaken is promising and fruitful for further results along this stream.

\section{ACKNOWLEDGEMENTS}

We thank very much the entire Italian and French MOOCs teams for their help and their crucial contribution to the design and management of the project. Without them neither the MOOCs nor this chapter would exist.

\section{REFERENCES}

Arzarello, F., Robutti, O. Sabena, C., Cusi, A., Garuti, R., Malara, N., \& Martignone, F. (2014). Meta-didactical Transposition: a theoretical model for teacher education programs. In A. ClarkWilson, O. Robutti, \& N. Sinclair (Eds.), The Mathematics Teacher in the Digital Era: An International Perspective on Technology Focused Professional Development (Vol. 2, pp. 347372). Dordrecht, The Netherlands: Springer.

Bender, W. N. (2012). Project-based learning: Differentiating instruction for the 21st century. Corwin Press.

Black, P., \& Wiliam, D. (2009). Developing the theory of formative assessment. Educational Assessment, Evaluation and Accountability, 21(1), 5.

Bozkurt, A., Akgün-Özbek, E., \& Zawacki-Richter, O. (2017). Trends and Patterns in Massive Open Online Courses: Review and Content Analysis of Research on MOOCs (2008-2015). The International Review Of Research In Open And Distributed Learning, 18(5). doi: http://dx.doi.org/10.19173/irrodl.v18i5.3080

Brooks, C., \& Gibson, S. (2012). Professional learning in a digital age. Canadian Journal of Learning and Technology 38(2). 
Carré, P. (2003). L'autoformation accompagnée en APP ou les sept piliers revisités. In P. Carré \& M. Tétart (dir.), Les ateliers de pédagogie personnalisée ou l'autoformation en actes, Paris, L'Harmattan

Carroll, J. B. (1963). A model of school learning. Teachers college record, 64(8), 723-733.

Chevallard, Y. (1999). L'analyse des pratiques enseignantes en théorie anthropologique du didactique. Recherches en Didactique des Mathématiques, 19(2), 221-266.

Conole, G. (2014). The 7Cs of learning design a new approach to rethinking design practice. In Proceedings of the 9th International Conference on Networked Learning (pp. 502-509).

Fidalgo-Blanco, A., Sein-Echaluce, M. L., \& García-Peñalvo, F. J. (2015). Methodological Approach and Technological Framework to Break the Current Limitations of MOOC Mode. Journal of Universal Computer Science 21, 712-734. Jaworski, B., \& Goodchild, S. (2006). Inquiry community in an activity theory frame. In J. Novotná, H. Moraová, M. Krátká \& N. Stehlíková (Eds.). Proceedings of the 30th Conference of the International Group for the Psychology of Mathematics Education (Vol. 3, pp. 353-360).

Goos, M. (2013). Sociocultural perspectives in research on and with mathematics teachers: a zone theory approach. ZDM, 45(4), 521-533.

Laurillard, D. (2016). The educational problem that MOOCs could solve: professional development for teachers of disadvantaged students, Research in Learning Technology, 24:1, 29369, DOI: $10.3402 /$ rlt.v24.29369.

Manlove, S., Lazonder, A. W., \& de Jong, T. (2007). Software scaffolds to promote regulation during scientific inquiry learning. Metacognition and Learning. 2: 141-155.

McAuley, A., Stewart, B., Siemens, G., and Cormier, D. (2010). The MOOC model for digital practice. University of Prince Edward Island.

Mishra, P., \& Koehler, M. J., (2006). Technological pedagogical content knowledge: A framework for teacher knowledge. Teachers college record, 108(6), 1017-1054.

Panero, M., Aldon, G., Trgalová, J. \& Trouche, L. (2017). Analysing MOOCs in terms of their potential for teacher collaboration: the French experience. Presented to TWG15 of the 10th Conference of European Research on Mathematics Education (CERME). Dublin, Ireland.

Rabardel, P. (1995). Les hommes et les technologies; approche cognitive des instruments contemporains. Armand Colin.

Robutti, O., Cusi, A., Clark-Wilson, A., Jaworski, B., Chapman, O., Esteley, C., Goos, M, Isoda, M, \& Joubert, M. (2016). ICME international survey on teachers working and learning through collaboration. ZDM Mathematics Education 48(5), 651-690.

Salmon, G. (2013). E-tivities: The key to active online learning. Abingdon, UK: Kogan Page.

Siemens, G. (2013). Massive Open Online Courses: Innovation in Education? In R. McGreal, W. Kinuthia, and S. Marshal (Eds.), Open educational resources: Innovation, research and practice (pp. 5-16). Vancouver: Commonwealth of Learning and Athabasca University.

Taranto, E., Arzarello, F., Robutti, O., Alberti, V., Labasin, S., \& Gaido, S. (2017). Analysing MOOCs in terms of their potential for teacher collaboration: the Italian experience. Presented to TWG15 of the 10th Conference of European Research on Mathematics Education (CERME). Dublin, Ireland. 
Taranto, E. (in preparation). MOOC's Zone Theory: creating a MOOC environment for professional learning in mathematics teaching education. PhD Dissertation. Turin University.

Trouche, L. (2004). Managing complexity of human/machine interactions in computerized learning environments: Guiding students' command process through instrumental orchestrations. International Journal of Computers for Mathematical Learning, 9, 281-307.

Velan, G. M., McNeil, H. P., Jones, P., \& Kumar, R. K. (2008). Integrated online formative assessments in the biomedical sciences for medical students: benefits for learning. BMC Medical Education, 8(1), 52.

Vygotsky, L. (1978). Mind in society. Cambridge, MA: Harvard University Press.

Wenger, E. (1998). Communities of practice: learning, meaning, and identity. Cambridge University Press.

Yuan, L., and Powell, S. (2013). MOOCs and Open Education: Implications for Higher Education. White paper. JISC CETIS. 